Iberian Journal of the History of Economic Thought

ISSN-e: 2386-5768

https://dx.doi.org/10.5209/ijhe.78661

\title{
El pensamiento estratégico en el mundo empresarial
}

Pedro Pablo Nuñez Domingo ${ }^{1}$

Recibido: 05/10/2021 / Aceptado: 27/10/2021

Resumen. Esta nota señala la importancia del nuevo libro de Juan Villena, Explorando el Pensamiento Estratégico que viene a cubrir un hueco en la literatura empresarial.

Palabras clave: Pensamiento estratégico; empresarialidad.

Clasificación JEL: M10

\section{[en] Strategic thinking in the business world}

Abstract. This note points out the importance of Juan Villena's new book, Exploring Strategic Thinking, which comes to fill a gap in business literature.

Keywords: Strategic Thinking; entrepreneurship.

JEL Classification: M10

Sumario: Introducción. La reflexión. Los casos. La cualificación. El diseño. Corolario.

Cómo citar: Nuñez Domingo, P. P. (2021). "El pensamiento estratégico en el mundo empresarial” en Iberian Journal of the History of Economic Thought 8(2). 173-177.

\section{Introducción}

Siendo la experiencia práctica uno de los veneros de la Ciencia Económica, las organizaciones que vertebran el sistema económico contribuyen también a la maduración de su pensamiento. El "mundo" empresarial ha perfeccionado conceptos, sistematizado ideas y elaborado modelos teóricos que intentan explicar cómo ve la realidad en la que actúa, cómo se organiza y se relaciona internamente y con su entorno, y cómo pretende alcanzar las metas que dan sentido a su existencia. Explorar ese pensamiento estratégico, reflexionando sobre teoría y experiencia práctica es también una aportación al desarrollo del pensamiento económico.

Por ello, esta nota quiere señalar la importancia del nuevo libro de Juan Villena: Explorando el Pensamiento Estratégico. Un viaje... para quien se siente emprendedor e innovador, Editorial Sanz y Torres, Madrid, 2021, Tomo I 556 págs., Tomo II 708 págs., ISBN (obra completa): 978-84-18316-40-1 .

En la extensa y variada literatura sobre el universo empresarial, la obra de Juan Villena viene a cubrir un hueco. Puede decirse que Explorando el Pensamien- to Estratégico es el manual que se echaba en falta, aunque, desde luego, es algo más que un manual.

Todo emprendedor, y todo gerente, para llevar adelante sus propósitos tiene en primer lugar que decidir qué producto o servicio ofrece para satisfacer qué necesidades, lo que le lleva a situarse en un campo específico de actividad, en un sector económico. También le será útil conocer las características de ese sector, sus relaciones con otros sectores y las peculiaridades específicas que tiene su empresa. Después tendrá que decidir sobre los recursos de que dispone, materiales, financieros y personales y la mejor manera de optimizarlos, es decir cómo organizar su empresa. Por último, tiene que plantearse cuál es su meta y cómo alcanzarla, si el servicio o producto que ofrece tiene alguna novedad, es innovador, o si se plantea seguir a otras empresas con un coste menor para sus clientes, es decir tiene que posicionar su empresa.

El autor concibe su obra "como un libro de viajes por el mundo de la empresa, tanto para orientar al profesional que ya vive sumergido en ese mundo, formando parte de él, como también al estudioso que se adentra en su exploración porque se siente atraído a comprender lo que le rodea y condiciona su vida".

Ha sido profesor de Historia Económica (U.P. Comillas) y de Pensamiento Económico Latinoamericano (U.A. Madrid), Directivo del INI-TENEOSEPI y Experto de la UE.

ORCID: 0000-0003-4028-1006

Email: milppn@gmail.com 


\section{La reflexión}

Como guía orientadora, en lo que podemos denominar manual de estrategia, la obra está compuesta de tres "libros", los dos primeros, en el Tomo I, constituyen lo que el autor denomina "el bagaje" de conocimiento, el tercero, en el Tomo II marca "el camino".

El Libro Primero examina los sectores de actividad. Partiendo de la Clasificación Nacional de Actividades Económicas (CNAE), ordena la diversidad sectorial en tres "supra-categorías primordiales": i) el mundo del Consumo, que engloba tanto bines como servicios, ii) la Gran Industria de bienes, que tendemos a denominar simplemente como industria, y iii) las Operadoras, que por extensión incluye a los "Servicios de Soporte".

Cada una de esas supra-categorías las descompone en macro-sectores o sectores homogéneos de bienes o servicios situados entre el Recurso Natural y su aplicación final:

- El Consumo en los macro sectores Bienes de Consumo (que engloba Agricultura, Ganadería y Caza, Silvicultura y Pesca, y sus industrias manufactureras) y Servicios de Consumo (Comercio, Hostelería y Entretenimiento).

- La Industria en Bienes Básicos (Industrias extractivas y manufactureras y sus Recursos Naturales), Componentes y Bienes de Equipamiento Menor (industrias manufactureras) y Bienes de Equipamiento Complejos (industrias manufactureras, ingeniería y construcción).-

- Las Operadoras en Servicios de Soporte Estructural (Suministros energéticos, agua y reciclaje; Transporte, y Comunicaciones), Servicios de Soporte al Sistema (Financieros, de Seguro e inmobiliarios, y otras actividades de apoyo) y Servicios de Soporte Social (Sanidad y asistencia social, y Educación).

A esta ordenación según categorías empresariales sigue un análisis de "la caracterización individualizada de ese espectro de sectores, identificando las semejanzas y diferencias entre ellos" para comprender su funcionamiento específico considerando: el Proceso productivo, la Tecnología, la Casación territorial de la oferta y la demanda, los Factores esenciales en la Operación y la Oferta, y las Fuerzas Motoras de Cambio de escenario.

Sigue el libro primero con el estudio de "aquello que determina el atractivo de un sector para el Empresario, el Inversor o el Estado": su potencial y los vínculos entre sectores. Lo que le sirve para proponer una perspectiva complementaria a la homogeneidad del producto identificando agrupaciones que se mueven al unísono. Este análisis se ilustra con esquemas comentados de los siguientes "sectores mixtos": la moda; el automóvil; aeroespacial; las obras e instala- ciones; el turismo; la defensa, seguridad y protección civil; las concesiones; la energía; la comunicación y el conocimiento, y la salud.

Completa este primer libro una reflexión sobre los cambios que está experimentando la diversidad empresarial, considerando "los tres pilares sobre los que se asentó el éxito de una familia de homínidos más evolucionados frente a otras más antiguas, el fuego, el lenguaje y la herramienta", que las aportaciones del intelecto humano nos presenta hoy como energía limpia, comunicación digital, y robótica inteligente más nuevos materiales.

El Libro Segundo aborda "la esencia de las organizaciones empresariales y su complejidad" siguiendo "cuatro pasos": el perfil, la cohesión, la decisión y la sensibilidad. Si en el libro primero el autor ha profundizado en la actividad, en el libro segundo se focaliza "en la relación entre aquellos que constituyen la empresa y en cómo interactúan entre sí y con terceros hacia lograr el objetivo de esta".

El perfil con el que la Propiedad y la Gestión pretenden que su empresa sea reconocida es "el Posicionamiento". En el camino progresivo de conocimiento de la empresa (que puede extenderse al concepto más amplio de "institución"), comienza analizando "la propiedad" (incluyendo consideraciones sobre el "Private Equity" y la consideración del Estado como empresario), los inversores, y los comportamientos de la propiedad y la gestión en cuanto a valores y políticas y respecto a las realizaciones (misión, posicionamiento y estrategias), deteniéndose también en la consideración de la empresa individual y las agrupaciones de empresas.

La cohesión lleva al autor a analizar el gobierno de la empresa: sus órganos, la delegación de las decisiones, el equilibrio de poderes, y los condicionantes de la propiedad en el modelo de gestión aplicable a la empresa. Se detiene en el organigrama, y en el funcionamiento de la organización, haciendo hincapié en la personalidad del CEO y la función del "Controller". Profundiza en el "modelo de gestión" y en como este modelo contempla su acción interior sobre el capital humano y su proyección al exterior, incluyendo consideraciones sobre las Asociaciones empresariales y las Organizaciones sindicales.

La Decisión permite hacer un recorrido por la delegación y la responsabilidad, su regulación, y el sentido de un sistema de planificación, seguimiento y control, explicando su ciclo y sus indicadores.

La Sensibilidad es una reflexión acerca del valor que aporta a la gestión y sus expectativas el compromiso integrado de los valores sociales respecto al medioambiente, la responsabilidad ante la sociedad y el comportamiento ético. Compromisos voluntarios y regulación, lucha contra el cambio climático, desarrollo económico, sostenibilidad, economía circular presión social, principios y modelos de información, así como el papel de inversores, financiadores y organismos (Naciones Unidad, Unión Europea, OCDE, Banco Mundial, Instituciones y 
Asociaciones) son aspectos incluidos en el tratamiento de este apartado.

El Libro Tercero "La Reflexión sobre la Estrategia y la Excelencia" recoge todos los aspectos del Posicionamiento y propone "cómo alcanzarlo o mantenerlo". Explica "cómo se configuran en la práctica las distintas respuestas empresariales a una situación, expectativas y objetivos, según el área de actividad" y analiza "cómo ha de ser la ejecución de la decisión y sus pasos ante y post". Hace primero un repaso crítico de los 50 años de Pensamiento Estratégico, que "tuvo su Big Bang con Peter Drucker", revisando sus conceptos y aportaciones principales (las matrices de Boston Consulting Group y Mc Kinsey, Factor Clave de Éxito, Cadena de Valor, Ventaja Competitiva, modelos DAFO, PESTEL y las cinco Fuerzas, las Barreras de Entrada y de Salida, la matriz de las Estrategias Genéricas, los Grupos Estratégicos, los modelos del Océano Rojo y Océano Azul, el modelo Canvas), para presentar después "los pasos del Proceso a través de los cuales el Pensamiento estratégico se conforma y conduce a la acción, según la visión del autor, y hasta su estado final de materialización": la Preparación, la Encrucijada (que conforman el Plan, el Marco Estratégico), la Clave en el Camino y el Bagaje y la Acción (que configuran el Acto esencial, la Implantación).

La Preparación, además de la formación y el diseño del proceso, incorpora también "el Punto de Partida", que para el autor es "la Excelencia". Una perspectiva distinta a la tradicional basada en competencia y ventaja, orientada sobre todo a la supervivencia. Requiere comprender el sector, los factores esenciales de la actividad empresarial (sus flujos físicos y económicos, y el territorio en que se despliega), la Fase del Escenario en que se encuentra y los Moduladores de su Atractivo. Conocido el sector, precisa también un diagnóstico de la empresa, sus limitantes y soportes, e integrar ambos diagnósticos, del sector y de la empresa.

La Encrucijada exige identificar el Destino y los Caminos para alcanzarlo. El destino es "el Posicionamiento que pretenda nuestra organización empresarial y los Caminos las distintas Estrategias posibles para llegar a él según Categorías". Los gestores deberán manifestar a la propiedad si consideran realista la Visión y la Misión, y si consideran o no factible el posicionamiento. Se detiene en cómo definir el posicionamiento, y en cuales son las preguntas "a las que una estrategia, un modelo de actuación coherente, deber dar respuesta" y presenta la figura figura que considero más presentativa de la obra, el árbol de estrategias: "seis troncos, las seis categorías estratégicas (Cualificación, Viabilidad, Sostenibilidad, Segmentación, Territorialidad y Modo de Desarrollo), que hunden sus raíces en los tres Vectores de sucesiva formulación del Posicionamiento empresarial (Adaptación, Configuración y Progreso), y despliegan su copa de Estrategias y sus variantes, que actuarán so- bre la cadena y sobre la oferta de la Empresa conforme a las soluciones que requiere el Posicionamiento adoptado".

La Clave en el Camino es aquello de lo que depende "que alcancemos o no el Destino". Debe buscarse "entre los Programas del Plan" seleccionando, ordenando y priorizando. Además de la identificación de elementos para la selección y de los factores a considerar para ordenar las prioridades, el autor reseña variables, tasas y ratios económicos para que el lector discrimine "ante las múltiples ratios y tasas que utiliza el mundo financiero para aproximarse a evaluar y comparar el atractivo de una inversión".

El Bagaje y la Acción desarrolla tres aspectos: i) lo que se necesita para que el viaje discurra adecuadamente, que el autor denomina "los condicionantes", atendiendo a las tres fases que habrá que transitar (Viabilidad, Inversión y Explotación), ii) la disponibilidad de los recursos financieros, indagando en la relación con inversores y financiadores, la minimización de los riesgos, y cómo estructurar la financiación y la cooperación, y iii) la clave "para conferir la factibilidad a ese proyecto o actuación y que alcance su materialización": las personas.

Estos tres libros, que conforman lo que hemos referido como manual, para el autor "forman parte de La Reflexión", y los describe, aplicando la similitud a un libro de viajes, destacando que "el Libro Primero es "el viaje por el universo de la diversidad empresarial, lo común, lo distinto y los vínculos, los mitos, la realidad y los vectores de futuro"; el Libro Segundo es el viaje "por la empresa en sí como grupo humano que habita ese mundo, los conflictos y sus bondades, el poder y la responsabilidad, la delegación y la iniciativa, la propiedad y la gestión"; el Libro Tercero indaga "sobre el destino de ese grupo, la encrucijada, la elección del camino......para llegar a donde se quiere".

Es de agradecer que el autor, siguiendo el camino emprendido por Peter Drucker, se haya separado de analogías militares para su aportación al mundo de la empresa (sería también más constructivo que el mundo cultural y el mundo político se desprendiera de esas analogías y no asimilaran la dicotomía amigo-enemigo a la realidad político-social).

Decía que la obra es algo más que un manual, ese algo más lo aportan dos características adicionales: por un lado, la aportación de la propia experiencia del autor en la revisión crítica de los contenidos fundamentales del pensamiento estratégico, que ofrecen al lector (emprendedor, gestor, estudioso o lector interesado) puntos de vista para suscitar el propio discernimiento de quien se interese por esos contenidos; por otro lado la exposición de cuatro casos prácticos, donde puede verse en la experiencia real la aplicación de todos los conceptos, la verificación de validez de ese "árbol de estrategias" que he reseñado como imagen más representativa de la parte dedicada a la reflexión, del manual que incluye la obra. 


\section{Los casos}

El Caso I ofrece el análisis de la evolución de la principal corporación española, el Grupo INI/TENEO/ SEPI, de acuerdo con la denominación sucesiva de la misma, entre los años 1983-2010. Este caso tiene dos partes, la primera, incorporada al Tomo I, donde se indaga sobre los sectores y las organizaciones, explica la evolución del grupo, desde lo que venía llamándose en la literatura económica sobre el INI, un aluvión de empresas, consecuencia de las incorporaciones de empresas en crisis desde finales de los años 60 y década de los 70, en orden a la paz social en una coyuntura de crisis económica y transformación política, a una agrupación de empresas más racionalizada durante los años 80 , coincidiendo con el período de la reconversión industrial, en el camino a una corporación rentable. En la segunda mitad de los años 90 se produce un cambio de visión del accionista, para entrar en un proceso de desinversiones (el período de privatización, que tiene su auge entre 1998 y 2005), seguido de unos intentos de racionalización y reordenación del sector público empresarial, solo materializados en parte, hasta 2010. Cabría recordar que desde 2011 se producen cambios en el gobierno con las elecciones legislativas, que van a afectar también a la visión del accionista sobre el grupo, entrando en un nuevo período que ya no es objeto de estudio en esta obra.

La perspectiva de esta primera parte es la corporativa, la estrategia seguida desde la cabecera para articular su cartera, incluyendo también el análisis de consecuencias deseadas (concentraciones en siderurgia, transporte aéreo y aeroespacial), consecuencias no deseadas (energía), y procesos pendientes (construcción naval).

La segunda parte de este primer caso tiene como perspectiva las estrategias específicas en las distintas empresas (bienes básicos y equipamiento, servicios de soporte y consumo), con un detenimiento, coherente con lo señalado en la primera parte, en la siderurgia, aeronáutica y espacio, electricidad y transporte aéreo.

Este caso, además de las enseñanzas sobre la aplicación del pensamiento estratégico, como se ha señalado, tiene, desde mi punto de vista, un valor adicional, por el complemento que supone para la literatura sobre la empresa pública en España, poniendo de manifiesto la gestión realizada, que en muchos casos, incluyendo las relaciones laborales y acuerdos sociales, ha sido pionera, independientemente de otras valoraciones, en la aplicación de modelos de gestión en la empresa española.

El segundo caso, "ENCE y Uruguay 1993-2006. Visión e Innovación", recoge la propia experiencia del autor, como CEO de la compañía durante esos años, y tiene, a su juicio las siguientes utilidades: i) "cuenta cómo fue ese descubrimiento propio de cómo actuar, trepando hasta sus últimas ramas por el árbol de estrategias", lo que permite apreciar gran parte de la base de las reflexiones del autor; ii) "cuenta cuándo y de qué forma se fue produciendo esa formulación y también cómo llevarla a la práctica, qué condicionantes habría que superar y hasta donde se materializó"; iii) "ver con naturalidad de qué forma se van revelando al gestor las vinculaciones de su actividad inmediata con otras"; iv) ver la complejidad de las Organizaciones empresariales, en lo que se refiere a la relación gestores-propiedad, a la diferenciación entre accionistas, y a aspectos de su modelo de gestión; v) "invita al lector a cavilar sobre los porqués de las personas y las organizaciones"; vi) "profundizar en las vinculaciones entre sectores más allá de la actividad originaria de la empresa"; vii) reflexionar sobre "el papel de la inversión extranjera sobre un país en los procesos de traslación del aparato productivo", y viii) "servir de soporte de otra reflexión del autor: ¿cómo da valor una gestión sensible a lo social y ambiental?" (recogida en el Libro Segundo).

Deseo llamar la atención sobre el punto de la inversión extranjera, porque también permite encontrar elementos que forman parte de la literatura sobre desarrollo económico, sirviendo de referente factual, y de referencia también para los aspectos éticos, sociales y ambientales.

El caso tercero es una muestra de 96 casos empresariales reales de 2015. La elección de casos fue realizada por los alumnos del autor en el máster que supuso su incursión en la docencia. Este universo "va a servir para tres fines: completar con esos casos y con la identificación de la estrategia que hay detrás de cada proyecto, la pluralidad de soluciones en el espectro de sectores; comprender las inquietudes y puntos de interés de las nuevas generaciones y la percepción del futuro que hay detrás de su selección, y contrastar en qué medida, ese futuro por ellos dibujado confirma o no las tendencias en la elección de las ramas en el árbol de estrategias".

El caso cuarto tiene un propósito diferente, "el autor le propone al lector dejar de pretender ser su guía, para pasar a ser simplemente un compañero en una última etapa del viaje". Para ello se ha fijado en el deporte profesional, "un territorio sobre el que seguramente no tiene más experiencia que el lector". De esta forma el autor va haciendo preguntas y sugiriendo respuestas que permiten ir configurando las características de una actividad especial en la que también son aplicables los conocimientos que se han venido exponiendo en la obra, como demostración de que toda actividad precisa de un pensamiento estratégico.

\section{La cualificación}

Ya he señalado que el autor fue CEO de Ence durante el período en que se estudia esta empresa en el Caso segundo. También tuvo una posición en primera línea para la exposición del Caso primero, pues fue director de Planificación y Control en el grupo INI los años anteriores a su paso a Ence. En la presenta- 
ción de su biografía en la solapa de la obra se añade también su experiencia como emprendedor (creó una consultora especializada en confluir actividad empresarial, Lucha contra el Cambio Climático y Responsabilidad Social), como asesor del Private Equity 3i, y como docente (conferencias y seminarios en cursos de posgrado. Además, entre otras referencias, ha sido Presidente de la Asociación Española de Celulosa, Papel y Cartón, y es Académico correspondiente en la Academia Nacional de Ingeniería de la República Oriental del Uruguay, en reconocimiento de su labor realizada en este país.

Son referencias que avalan la cualificación del autor para los contenidos que aborda, debiendo de resaltar también su capacidad de trabajo, que se evidencia al contemplar la ingente información y el esfuerzo para ofrecerla también visualmente, en las 1264 páginas de la obra.

\section{El diseño}

La edición tiene un esmerado diseño y unas sugerentes portadas, y debe destacarse su realización tenien- do en cuenta que incorpora 552 figuras de familias de esquemas, cuadros y gráficos (242 en el Tomo I y 306 en el Tomo II. Estas características son idóneas para la edición digital, aunque la dificultad del diseño esta bien solucionada en la edición en papel.

\section{Corolario}

La admiración que refleja esta nota por los contenidos de la obra, cubriendo una necesidad editorial en el ámbito del pensamiento estratégico, por las sugerencias que ofrece al lector, por la aceptación de discrepancias y puntos de vista diferentes a lo que se presenta, por la originalidad de las imágenes que facilitan y guían la comprensión de los contenidos, por los mensajes que contiene y por el diseño del conjunto, pueden entenderse por el conocimiento que he tenido la oportunidad de tener de su proceso de elaboración, desde los primeros bocetos hasta su revisión final. Pero confío en que será también compartida por todos aquellos que se acerquen, lean y utilicen este manual-guía de viaje del pensamiento estratégico en las organizaciones. 